\title{
CONDUZINDO FOCUS GROUP COM IDOSOS: COMPREENDENDO COMO INTERAGEM E QUEREM APRENDER A UTILIZAR SMARTPHONES
}

\section{CONDUCTING FOCUS GROUP WITH ELDERLY PEOPLE: LEARNING HOW THEY INTERACT AND WANT TO LEARN TO USE SMARTPHONES}

\author{
Eron Rocha ${ }^{1}$, Me. \\ Stephania Padovani ${ }^{2}, \mathrm{Dr}^{\mathrm{a}}$. \\ (1) Universidade Federal do Paraná (UFPR) \\ e-mail: eronmoreno@gmail.com \\ (2) Universidade Federal do Paraná (UFPR) \\ e-mail:s_padovani2@yahoo.co.uk
}

Palavras-chave: usuários idosos, ensino-aprendizagem de smartphones, grupo focado

Este artigo tem por objetivo levantar as sugestões do público idoso que podem contribuir com noções de ensinoaprendizagem na elaboração de um curso básico de smartphones. O método utilizado foi o grupo focado, com a participação de 9 idosos. Os resultados são informações relacionadas à aprendizagem de smartphones, que podem contribuir para a elaboração de um mini-curso de smartphones para idosos.

Key-words: elderly users, teaching-learning smartphones, focus group

This article aims to raise the suggestions of the elderly public that can contribute with notions of teaching-learning in the elaboration of a basic course of smartphones. The method used was the focus group, with the participation of 9 elderly people. The results are information related to the learning of smartphones, which can contribute to the development of a mini-course of smartphones for the elderly people.

\section{Introdução}

O Brasil tende para se tornar um país de população majoritariamente idosa. O Censo 2010 do IBGE, constatou 24,85 milhões de pessoas com mais de 60 anos no Brasil, representando 12,6\% da população. Este mesmo censo informou que o grupo de pessoas de 60 anos ou mais será maior que o grupo de crianças com até 14 anos já em 2030. A pesquisa mais recente encomendada pelo Banco Mundial a respeito do envelhecimento da população brasileira indica que esta corresponde a quase $20 \%$ do poder de compra do país

(GRAGNOLATI et al., 2011), estimulando 


\section{$16^{\circ}$ \\ ERGODESIGN USIHC CINAHPA}

diversos setores, dentre eles o de tecnologia, no qual incluem-se os smartphones.

Os smartphones são utilizados para as mais diversas tarefas do dia-a-dia por pessoas de diversas idades, dentre elas incluem-se as pessoas de 60 anos ou mais. As fabricantes de smartphones nos Estados Unidos estão atentas para essa tendência, mas pouco se vê nos pacotes de ferramentas de acessibilidade em smartphones no Brasil.

A configuração da interface de smartphones não pensada no público idoso compromete a utilização destes dispositivos móveis por este público. A possível frustração causada pelas alterações decorrentes do envelhecimento na interação com o smartphone pode resultar na desistência do uso deste aparelho. A falta de usabilidade e de pacotes de acessibilidade nos smartphones no Brasil pode excluir digitalmente o idoso de meios sociais.

É percebida a dificuldade dos idosos no aprendizado da utilização de smartphones devido à falta de acessibilidade da interface destes (TANG et al., 2013). Considerando essa dificuldade, surgiu a pergunta: como os idosos gostariam de aprender a utilizar os smartphones?

Este artigo pretende levantar sugestões do público idoso que podem contribuir com noções de ensinoaprendizagem na elaboração de um curso básico de smartphones. Para entender quais são as experiências desse público com o aparelho e quais são as expectativas em relação à aprendizagem deste, para obter esses dados foi utilizada a dinâmica focus group.

Foi obtido como resultado deste trabalho: a reunião de assuntos relevantes em relação ao ensinoaprendizagem de smartphones para idosos e sugestões específicas de participantes que fazem parte desse público. Após essa primeira seção, que se trata da introdução, este artigo discorre em 5 seções sequenciadas e numeradas de 2 a 5 , desenvolvidas da maneira que segue:

\section{Idosos e a interação com o smartphone}

Esta seção aborda como se dá a interação do idoso com a tecnologia touch screen e funções do $16^{\circ}$ Ergodesign - Congresso Internacional de Ergonomia e Usabilidade de Interfaces Humano Tecnológica: Produto, Informações Ambientes Construídos e Transporte

$16^{\circ}$ USIHC - Congresso Internacional de Ergonomia e Usabilidade de Interfaces Humano Computador

CINAHPA | 2017 - Congresso Internacional de Ambientes Hipermídia para Aprendizagem.

\section{smartphone.}

\section{Método}

Na terceira seção é relatada a preparação para a realização do focus group.

\section{Resultados}

Na quarta seção constará o resultado obtido com a aplicação da dinâmica focus group, questões levantadas pelo pesquisador, além de discussões e sugestões feitas pelos participantes.

\section{Conclusão}

Concluída a aplicação do método e a obtenção de resultados, nesta última seção discute-se a importância do conhecimento das necessidades e expectativas dos usuários idosos na aprendizagem de smartphones.

\section{Idosos e a interação com smartphones}

Em uma revisão bibliográfica, Phiriyapokanon (2011) concluiu que idosos enfrentam dificuldades no uso de pequenos dispositivos digitais. $\mathrm{O}$ autor constata que pessoas acima de 60 anos, encontram problemas na interação com botões e textos de tamanhos considerados pequenos por essas pessoas, e, portanto, inapropriado para eles.

Além de problemas de interação relacionados aos elementos de interface, Phiriyapokanon (2011) também relatou que os idosos encontram problemas de entendimento no que eles consideram ser uma sobrecarga de funções complexas que há nos dispositivos de interação móveis como os menus.

Como fator facilitador de aprendizado, Phiriyapokanon (2011) explicou que idosos que têm experiências com celulares, estão mais suscetíveis de aprender novos dispositivos móveis com mais rapidez.

A tecnologia touch, é utilizada em diferentes dispositivos, desde máquinas de cupons, displays de quiosques, até tablets e smartphones. As touch screens, amplamente consideradas intuitivas, se tornaram populares entre pessoas de diferentes idades, incluindo os idosos (PHIRIYAPOKANON, 2011).

Com um estudo para investigar como idosos 


\section{$16^{\circ}$ \\ ERGODESIGN USIHC CINAHPA}

aprendem smartphones naturalmente, Tang et al. (2012) pesquisaram sobre as motivações desse público em aprenderem este aparelho. Foi feito um estudo com participantes acima de 60 anos, os autores relataram que a motivação dos participantes em aprenderem smartphones pareceu ser influenciada pelos círculos sociais.

Durante o estudo dos autores Tang et al. (2012), algumas tarefas foram solicitadas aos participantes e aquelas que se tratavam de interação entre amigos, aparentou maior entusiasmo entre os participantes. Como resultado os autores constataram que o método de aprendizado mais utilizado pelos idosos foi o: tentativa e erro.

Não foi encontrado na literatura disponível, questionamentos aos idosos sobre quais as melhores formas que estes gostariam de aprender smartphone. E este é o objetivo deste trabalho, que é parte da dissertação de Rocha (2017), que após observar idosos do curso de informática básica para idosos da Companhia de Informática do Paraná - CELEPAR, aplicou o método descrito na seção a seguir.

\section{Método}

Focus group ou grupo focado é um conhecido método qualitativo utilizado frequentemente por pesquisadores para coletar dados de estratégia de mercado (marketing). É uma dinâmica criada por um grupo pequeno de pessoas escolhidas e guiadas por um moderador que pode fornecer uma visão profunda sobre temas, padrões e tendências (MARTIN \& HANINGTON, 2012).

O objetivo dessa dinâmica foi tomar conhecimento das experiências de idosos em relação ao curso já realizado sobre informática básica, saber de suas experiências e necessidades em relação aos smartphones, e também suas expectativas em relação à aprendizagem desses aparelhos.

Antes da realização da atividade, foram esclarecidos os termos de participação aos presentes: Termo de Consentimento Livre e Esclarecido, o pesquisador esclareceu sobre o que se trata o focus group, o objetivo dessa pesquisa, $16^{\circ}$ Ergodesign - Congresso Internacional de Ergonomia e Usabilidade de Interfaces Humano Tecnológica: Produto, Informações Ambientes Construídos e Transporte

$16^{\circ}$ USIHC - Congresso Internacional de Ergonomia e Usabilidade de Interfaces Humano Computador

CINAHPA | 2017 - Congresso Internacional de Ambientes Hipermídia para Aprendizagem. que os dados obtidos serão tratados de forma anônima e que os voluntários podem se recusar a participar a qualquer momento sem que acarrete nenhum prejuízo a eles.

A equipe de pesquisadores foi composta por 3 pessoas: o pesquisador no papel de moderador, uma assistente e um roteirista, cada um possuindo um guia de tópicos, as discussões foram conduzidas pelo moderador, mas todos contribuíram com as discussões a fim de gerar verbalização dos participantes.

Foi avisado anteriormente à coordenadora do projeto de Inclusão Social da Pessoa Idosa - que ministra os cursos básico de informática para idosos - que essa atividade não conte com a presença dos instrutores, e assim na sala onde a atividade ocorreu na CELEPAR, estavam apenas a equipe de pesquisadores e os participantes.

Foram convocados até 11 ex-alunos pela coordenadora do projeto, 10 compareceram mas apenas 9 realmente participaram da atividade, um dos participantes assim que chegou precisou se retirar e só voltou ao fim da atividade. Para uma comunicação mais direta e ampla, optou-se por dispor os participantes em um círculo, com cadeiras para sentarem.

Em uma mesa ao centro foram dispostos bolos, torta salgada, sucos, refrigerante e café para os participantes se servirem à vontade. Este tratamento faz parte da abordagem utilizada com este público que é explicada a seguir.

\section{Abordagem no focus group}

Com a experiência obtida durante a observação, foi possível elaborar a abordagem utilizada no focus group. Ao presenciar o uso de analogias durante as aulas do curso, foi pensado que para algumas questões seria feito também o uso de analogias, até mesmo durante a discussão gerada para tornar o conteúdo discutido mais esclarecedor para os participantes.

Foi observado durante o curso de informática básica, ao realizar atendimentos individuais ou tirar dúvidas, que este público valoriza a atenção
Realização:

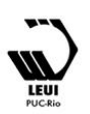




\section{$16^{\circ}$ \\ ERGODESIGN USIHC CINAHPA}

$16^{\circ}$ Ergodesign - Congresso Internacional de Ergonomia e Usabilidade de Interfaces Humano Tecnológica: Produto, Informações Ambientes Construídos e Transporte

$16^{\circ}$ USIHC - Congresso Internacional de Ergonomia e Usabilidade de Interfaces Humano Computador

CINAHPA | 2017 - Congresso Internacional de Ambientes Hipermídia para Aprendizagem. dispensada a eles, por essa razão é importante que ao realizar perguntas, o pesquisador esteja direcionado à pessoa que começou a responder.

Enquanto um participante está falando e outro participante começa a falar, é importante continuar olhando e escutando aquele que começou a falar primeiro até que ele finalize a sentença. Após ouvir um dos participantes, deve-se então localizar o participante que falou enquanto o outro estava respondendo e perguntar o que foi falado por ele, para que contribua também com a atividade.

Deixar de dar atenção a um participante para dar a outro que começou a falar, mesmo que este pareça contribuir com mais informações que o primeiro, pode gerar a ideia de que o pesquisador está ignorando o participante que começou a falar primeiro, e este não querer participar mais da atividade.

É fundamental saber ouvir o público idoso, eles têm muitas histórias para contar, e gostam de conta-las. É importante compreender que ao dispensar um tempo para ouvir o que o participante tem a dizer e interagir com ele, mesmo que não seja relevante ao tema de estudo, cria um laço de respeito, e mais o participante irá contribuir com a atividade.

Para uma atividade como o focus group, é importante medir até que ponto deixar que a conversa se desvie do tema. Com a observação foi possível entender que é preciso que o participante idoso termine ao menos a parte principal do que está sendo falado. $O$ pesquisador deve aproveitar o intervalo do final da conversa para voltar ao tema, antes que o mesmo participante ou outro continue a conversa fora do tema.

Um atributo importante para o focus group é estimular a verbalização dos participantes, para os participantes idosos um dos principais estímulos é aproximar o conteúdo com o relacionamento deles com seus familiares. Por exemplo, ao perguntar se gostariam que no novo curso de smartphone tenha conteúdo sobre redes sociais, foi perguntado também se acham importante a comunicação com os parentes, houve muitas respostas e empolgação por parte dos participantes.

Foi observado que durante o coffe break das aulas de informática básica, os alunos se sentiam à vontade para conversarem entre si, para criar um ambiente favorável à verbalização foi providenciado pelo pesquisador doces, salgados e bebidas, foi esclarecido para os participantes que podem se alimentar livremente. Não foi possível constatar que a presença de alimentos auxiliou no estímulo da verbalização, mas houve muitos elogios pela presença e qualidade dos alimentos.

\subsection{Elaboração dos momentos do Focus Group}

Os dados coletados na observação contribuíram para elaborar a abordagem a ser utilizada no focus group, e assim foi pensado como seria o primeiro contato com os idosos durante essa atividade.

Optou-se por realizar uma atividade de apresentação que para este estudo será chamada como: quebrando o gelo, que serviu principalmente para a apresentação da equipe de pesquisa.

Com os dados obtidos na observação do curso, foi possível pensar em quais informações seriam necessárias para elaborar um curso de smartphone que atenda às expectativas do público ao qual ele é direcionado. Dessa forma chegou-se a conclusão de que primeiro é preciso entender quais são as experiências e impressões que esse público tem em relação aos smartphones. Assim também foi pensado que é preciso levantar questões específicas para saber quais são as expectativas em relação ao novo curso de smartphone para idosos.

Para não haver confusão quanto ao tratamento do conteúdo a ser discutido no focus group, foi pensado então quais momentos teriam na atividade para que o conteúdo possa ser abordado de forma fluída. Para ter um guia como suporte para as pautas a serem abordadas, foi planejado 3 momentos para ocorrerem sequenciados:
$1^{\circ}$ momento - Quebrando o gelo
$2^{\circ}$ momento - Experiências e impressões em relação aos smartphones $3^{0}$ momento - Expectativas em relação à aprendizagem de smartphones

Realização:

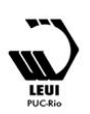




\section{$16^{\circ}$ \\ ERGODESIGN USIHC CINAHPA}

Para cada momento foi elaborado o que deveria acontecer, tópicos a serem discutidos e perguntas a serem feitas. A forma como ocorreram esses momentos é relatada na subseção seguir, com as informações mais importantes coletadas nessa atividade.

\section{Resultados}

\section{$1^{\circ}$ Momento - Quebrando o gelo.}

Este primeiro momento é referente ao início da atividade focus group, planejada para que todos os envolvidos na atividade possam se conhecer melhor, o objetivo desse momento é que os participantes se sintam mais à vontade para expressarem suas opiniões sobre os assuntos da atividade.

Primeiramente foi realizada a apresentação da equipe de pesquisa, em seguida foi explicado aos participantes os objetivos da atividade: ouvir o que os idosos têm a dizer e coletar contribuições para a construção de um curso de smartphone voltado para esse público. Foi solicitado que os participantes se apresentem e digam a razão pela qual procuraram o curso de informática da CELEPAR.

\section{$2^{\circ}$ Momento - Experiências e impressões em relação aos smartphones.}

O segundo momento do focus group foi composto por questionamentos pelos moderadores e relatos feitos pelos participantes sobre: interações experienciadas em relação ao smartphone, como os participantes aprenderam o que sabem em relação ao aparelho, como ensinariam ou que conselhos dariam para outro idoso.

Este momento também contemplou o uso do smartphone no cotidiano dos participante, houve também muitos relatos de dificuldades e receios. Foram coletados dados também a respeito de anotações para lembrar do caminho navegado no smartphone e personalização.

\section{Primeiros passos na interação com o smartphone}

Em relação às questões referentes ao primeiro contato e início de aprendizado com o smartphone, $16^{\circ}$ Ergodesign - Congresso Internacional de Ergonomia e Usabilidade de Interfaces Humano Tecnológica: Produto, Informações Ambientes Construídos e Transporte

$16^{\circ}$ USIHC - Congresso Internacional de Ergonomia e Usabilidade de Interfaces Humano Computador

CINAHPA | 2017 - Congresso Internacional de Ambientes Hipermídia para Aprendizagem. a maioria dos participantes tiveram ajuda de algum parente ou amigos para aprender algumas funções básicas como: ligar, atender, enviar mensagens e usar algumas redes sociais (e.g. Facebook).

A senhora 1 relatou já ter pago um parente para ter aulas de interação com o DIM: "eu paguei minha sobrinha para me dar aulas, ela resistiu em aceitar mas eu insisti, queria que ela levasse a sério pra me ensinar de verdade."

A Senhora 2 expôs que aprendeu por tentativa e erro, pesquisando no site de buscas Google e vídeos no site Youtube, além no próprio manual de instruções do aparelho, para entender como determinadas tarefas eram realizadas. Havia dois senhores não usuários de smartphone, entre eles, o Senhor 1 afirmou: "não sei mexer e nem tenho o aparelho, trouxe comigo o smartphone da minha mulher."

Quando questionados sobre como eles ensinariam outro idoso a usar o smartphone, a Senhora 1 respondeu: "primeiro ligar e colocar uma senha. Eu orientaria como fazer os movimentos gestuais, passo a passo, explicaria o que cada aplicativo faz: o que é esse clipe? O que faço com ele? Bem coisa de professor, o ruim do aprendizado é quando quem está ensinando faz pelo outro."

A Senhora 1 disse ainda que é interessante que o professor estimule o aluno a repetir a tarefa até que esta seja realizada corretamente, e finalizou: "deveria ter uma cartilha para iniciantes. $\mathrm{O}$ problema do manual de instruções impresso desses aparelhos é que vem em várias línguas, menos em português! " Em seguida o Senhor 2 completou: "os manuais não são suficientes porque não são autoexplicativos, deve haver uma valorização maior de professores e material impresso bem escrito."

Ainda sobre como ensinar outro idoso a usar smartphone, a Senhora 2 disse que: "mandava ir para uma escola! Eu orientaria os passos iniciais: como funcionam os botões e indicaria buscar tutoriais no Google." O Senhor 1 disse que além de ter conhecimento é preciso paciência para ensinar os idosos: "as minhas filhas não têm 


\section{$16^{\circ}$ \\ ERGODESIGN USIHC CINAHPA}

paciência para ensinar." O Senhor 3 enfatizou o início pelas funções básicas: "ensinar como mandar mensagem e até mesmo como fazer uma ligação a cobrar."

Com os dados obtidos nesse início da atividade, foi possível compreender que esse público necessita de auxílio de alguém com instruções para facilitar o aprendizado sobre o smartphone, e foi sugerido que esse ensino seja feito em um curso. Ficou clara a necessidade de que o ensino seja feito de modo paciente e de forma gradual partindo do básico, e que $o$ instrutor deixe que o aluno faça a ação e não fazer por ele. A verbalização dos participantes evidenciou também a importância de material impresso e em português.

\section{O uso do smartphone no cotidiano e dificuldades}

Quanto ao item relativo ao uso do smartphone no cotidiano dos participantes usuários do aparelho, eles responderam quais são as funções ou aplicativos que mais utilizam: Whatsapp (aplicativo que utiliza a conexão com a internet para a troca de mensagens), ligações e Facebook. Outros aplicativos e funções menos citados foi o uso de e-mail e o Waze (aplicativo que baseia-se em uma comunidade que compartilha informações de transito em tempo real, quando conectado à internet).

Os participantes foram questionados quanto às dificuldades com o aparelho, para este assunto houve uma grande quantidade de relatos. A Senhora 4 disse que: "ele já caiu da minha mão, as vezes a tela bloqueia ou trava e eu não sei o que fazer para destravar, outra coisa que acontece é a memória do smartphone ficar cheia e não sei resolver, e o aparelho fica lento."

O Senhor 4 utiliza apenas o smartphone da empresa em que trabalha, e expôs que: "quando o smartphone trava não sei o que fazer. Tenho várias dificuldades. Não sei como o problema começa e nem sei como resolver, também tenho dificuldade em anexar imagens pelo Whatsapp. Quando chega mensagens para atualizar algo eu não sei o que fazer." $16^{\circ}$ Ergodesign - Congresso Internacional de Ergonomia e Usabilidade de Interfaces Humano Tecnológica: Produto, Informações Ambientes Construídos e Transporte

$16^{\circ}$ USIHC - Congresso Internacional de Ergonomia e Usabilidade de Interfaces Humano Computador

CINAHPA | 2017 - Congresso Internacional de Ambientes Hipermídia para Aprendizagem.
Pelo menos 3 participantes relataram dificuldades em conseguir se conectar à internet móvel, alguns nem sabiam da existência desse recurso, como a Senhora 5: "em casa eu acesso a internet normal (wi-fi), mas quando saio de casa a internet cai e eu não consigo acessar! Dá vontade de jogar o aparelho na parede!" O Senhor 3 informou à Senhora 5 que deve-se acionar a internet móvel do smartphone, o mesmo participante aproveitou $\mathrm{e}$ adicionou seu relato: "Tenho uma dificuldade mediana para receber e enviar $e$-mails, principalmente para responder. Outra coisa que acontece é o sistema solicitar atualização e não sei como proceder."

Outros problemas com a interação foram relatados pela Senhora 3: "Já tive problemas com o Waze, tentei digitar e não saía nada, precisei usar o sistema de voz. Já tive problemas para configurar o alarme. Tem coisas que a gente acerta e nem sabe como fez." Para o Senhor 2 há também dificuldades na realização de uma videoconferência pelo smartphone: "a conexão é muito instável!" A Senhora 2 disse que a pouco tempo descobriu que em seu iPhone há uma trava que silencia o aparelho, e que ela ficou muito tempo sem saber por que ele estava mudo.

Houve dúvidas em relação à transferência de dados e carregamento da bateria. A Senhora 1 relatou não saber como o backup funciona: "quando o smartphone pede para fazer backup, eu não sei o que fazer!" A mesma participante disse não saber a razão pela qual a o smartphone esquenta e tem dúvidas sobre o carregamento da bateria do aparelho: "Quando devo recarregar a bateria? Devo esperar acabar tudo? E quando estiver carregando, por quanto tempo devo deixar lá?"

O Senhor 2 disse não saber como passar os contatos de agenda do aparelho para o chip. A Senhora 5 diz não achar respostas no aparelho: "as vezes eu não acho a agenda de contatos, como faço para conseguir a informação que eu quero? Por exemplo, como passo as fotos para o computador? O smartphone não me diz."

Houve relatos referentes à configuração do smartphone, como o da Senhora 2: "Não sei o que
Realização:

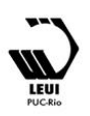




\section{$16^{\circ}$ \\ ERGODESIGN USIHC CINAHPA}

acontece, mas ele já desconfigurou várias vezes, precisou ir para a assistência técnica. Uma vez ativei a função de acessibilidade sem querer e não consegui reverter, as mensagens que apareciam eram em inglês!"

Com essas discussões foi possível entender que as funções mais utilizadas pelos participantes no smartphone são os aplicativos Whatsapp,

Facebook e a função de ligar. É importante saber o que esse público mais utiliza para se ter noção da atenção que deve ser dispensada a esse conteúdo no curso de smartphone.

De acordo com o que foi exposto pelos participantes, há dificuldades na configuração do smartphone como: o acesso à internet, alarme, som, o sistema de trava de tela e o esvaziamento da memória do aparelho. Ainda sobre a configuração, eles não sabem exatamente como é o funcionamento do backup e da transferência de dados para o computador. Os participantes também expressaram dificuldades em outros recursos como: anexar imagem em mensagens, atualização de apps, carregamento da bateria.

É relevante compreender as dificuldades do cotidiano na interação dos participantes com o smartphone, pois assim além de garantir espaço para esses assuntos no possível curso sobre esses aparelhos, o fato de terem mais dificuldade com esses recursos sinaliza aos instrutores uma explicação mais cuidadosa e atenciosa.

\section{Anotações e lembretes para a navegação \\ Foi perguntado aos participantes se sentem dificuldades para navegar no smartphone, em caso de resposta positiva, foi perguntado o que fazem para solucionar esta dificuldade. A Senhora 1 disse que precisa anotar em um caderno o passo-a-passo: "é muita informação e não lembro de tudo." A Senhora 2 relatou que não faz anotações: "vou tentando, se eu não conseguir desisto ou procuro no Google e Youtube."}

Essas respostas demonstram que alguns participantes necessitam de um suporte que sirva para anotações de atalhos ou caminhos na navegação das telas do smartphone. Este suporte $16^{\circ}$ Ergodesign - Congresso Internacional de Ergonomia e Usabilidade de Interfaces Humano Tecnológica: Produto, Informações Ambientes Construídos e Transporte

$16^{\circ}$ USIHC - Congresso Internacional de Ergonomia e Usabilidade de Interfaces Humano Computador

CINAHPA | 2017 - Congresso Internacional de Ambientes Hipermídia para Aprendizagem.

pode ser o mesmo material que conterá o conteúdo de aula: a apostila.

\section{Personalização}

Quando questionados sobre a personalização de seus aparelhos, os participantes relataram algumas preferências, como a Senhora 2: "não gosto de usar pastas, uso uma pasta apenas para colocar aplicativos que não utilizo muito. Os aplicativos mais utilizados ficam nas telas principais."

$\mathrm{O}$ assunto desencadeou alguns questionamentos para a Senhora 1: "Me confundo com os aplicativos duplicados que aparecem e ficam sobrando. Como que aparece 2 aplicativos do Facebook? Por exemplo: tem o aplicativo de $e$ mail que veio no aparelho e tenho o aplicativo do Gmail, qual devo usar? Sei utilizar a lixeira para jogar fora, mas qual eu devo apagar? Não uso as funções de personalização por receio de desconfigurar o aparelho. Gostaria de usar letras maiores, mas não sei colocar e tenho receio de estragar."

Alguns familiares auxiliaram na personalização conforme o pedido do usuário, como relatou o Senhor 2: "meu filho ajudou a mudar o fundo de tela inicial no smartphone. Mas agora eu quero mudar o fundo da tela de conversa do Whatsapp, colocar fotos que tenho na galeria de imagens, mas não sei como faz para alterar".

Com a discussão sobre personalização foi possível compreender que junto ao conteúdo da configuração é necessário que seja ensinado também como personalizar o aparelho para que o usuário consiga aplicar suas preferências.

\section{$3^{\circ}$ Momento - Expectativas em relação à aprendizagem de smartphones.}

No terceiro e último momento teve como objetivo colher dados das expectativas dos participantes em relação ao possível curso de smartphone para idosos. Nesse momento foi proposto que os participantes utilizem como base para discussão: o curso de informática básica e redes sociais da CELEPAR cursado por eles, para sugerir quais aspectos poderiam permanecer e quais deveriam ser alterados para o possível curso de smartphone.
Realização:

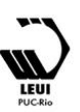




\section{$16^{\circ}$ \\ ERGODESIGN USIHC CINAHPA}

$16^{\circ}$ Ergodesign - Congresso Internacional de Ergonomia e Usabilidade de Interfaces Humano Tecnológica: Produto, Informações Ambientes Construídos e Transporte

$16^{\circ}$ USIHC - Congresso Internacional de Ergonomia e Usabilidade de Interfaces Humano Computador

CINAHPA | 2017 - Congresso Internacional de Ambientes Hipermídia para Aprendizagem.
Foram abordadas as preferências dos participantes em relação ao formato das aulas.

\section{Exposição de conteúdo}

Nas aulas de informática básica e redes sociais da CELEPAR o conteúdo da aula está em um computador conectado à um projetor multimídia, assim a tela do computador é exposta na parede. Os participantes concordaram sobre a utilização do projetor multimídia como meio para a exposição do conteúdo, mas no caso do curso proposto, uma câmera deveria ser utilizada para capturar as imagens do instrutor interagindo no smartphone.

A realização da interação dos alunos com o smartphone seria simultânea com a interação exposta pelo instrutor, como sugeriu o Senhor 3: "Acho importante o uso do projetor, e os alunos realizando a atividade em seus smartphones, juntos com a explicação do instrutor."

\section{Material impresso}

Em comparação com a apostila existente no curso de computadores, os participantes concordaram que será necessário um material semelhante, como exemplificou o Senhor 1: "Tem que ter uma apostila bem be-a-ba, começando do básico, bem rasteiro." A Senhora 1 foi mais específica e disse que poderia haver: "uma folha com todos os ícones: significado e função."

Com o consenso dos participantes, ficou reforçada a necessidade de haver uma apostila, e que nela ou em separado, tenha uma folha com as informações dos principais ícones e apps.

\section{Formato de sala de aula}

Quanto à disposição dos alunos em sala, foi consenso entre os participantes a ideia do formado circular, semelhante ao formato do focus group realizado e diferente do formato utilizado no curso de informática básica cursado anteriormente.

O Senhor 2 considera interessante o formato oval, a Senhora 2 pensou parecido e disse: "a concentração é melhor quando estamos dispostos em formato de círculo. Cada um pode ouvir e ajudar o outro." A Senhora 1 ponderou sobre o formato de círculo e a disposição de alunos em duplas: "Teria que fazer uma experiência. Um meio círculo seria interessante. Se estamos em dupla e nenhum dos dois souber resolver o problema, não adianta. Em semicírculo o aprendizado é melhor."

O Senhor 1, seguindo o exposto pelos demais participantes, concluiu: "o formato de "u" é melhor." Para esta discussão foi consenso entre os participantes que os alunos devem estar dispostos em formato de "u" no curso de smartphone.

\section{Duração do curso e tempo de aula}

Os participantes foram questionados sobre a duração e tempo das aulas do curso proposto, este item é importante não só por expor a preferência, mas também para evitar o cansaço dos participantes que pretendem participar do curso. Para a Senhora 1: "quatro dias seria um tempo bom, de preferência, de tarde. Eu iria com certeza."

O Senhor 1 disse preferir cinco dias, as Senhoras 2 e 3 sugeriram que as aulas poderiam ser realizadas duas vezes por semana durante algumas semanas, mas não souberam especificar quanto tempo duraria o curso. Após algumas discussões entre os participantes, estes concluíram que: quatro dias, em uma semana, seria o suficiente, a mesma duração do curso de informática básica já cursado pelos participantes.

Juntamente à discussão de quantos dias duraria o curso, os participantes foram questionados sobre quantas horas duraria a aula de cada dia, para esta questão o Senhor 2 disse que 3 horas (como foi no curso de informática básica) é o suficiente, o Senhor 1 opinou que: "3 horas está bom, por mim poderia ser até mais."

Ao final dessa discussão, os participantes concordaram que a duração de cada aula seria de 3 horas com a realização do curso no período vespertino, durante quatro dias.
Atendimento individual e melhores formas de tirar dúvida
No curso de informática básica para idosos da CELEPAR, existem momentos em que os instrutores e principalmente os monitores, vão até

Realização:

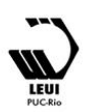




\section{$16^{\circ}$ \\ ERGODESIGN USIHC CINAHPA}

o aluno para tirar dúvidas, guiando este para que consiga realizar a tarefa proposta em aula. Em relação ao atendimento individual e melhores formas de tirar dúvida, o Senhor 1 disse: "esse tipo de atendimento ajuda muito, se tivesse um por aluno seria melhor", a Senhora 1 apontou que: "a ajuda do instrutor é sempre bom, ajuda a andar, mas nem sempre é necessário: às vezes precisamos tentar sozinhos. Um por aluno não acho que seria necessário."

Os participantes relataram que é importante o atendimento individual para solucionar dúvidas específicas de cada um: o participante pergunta diretamente sobre o que mais está com dificuldade, mesmo que não seja o assunto da aula. Alguns integrantes afirmaram que auxilia na aprendizagem as instruções passo-a-passo do monitor ou instrutor, quando esses são chamados para fazer o atendimento individual.

Foi consenso entre os participantes que esse atendimento individual ajuda na aprendizagem, considerado até necessário. Os participantes não souberam especificar uma quantidade exata de monitores para prestar esse auxílio, mas o Senhor 3 disse: "no curso que eu fiz de computador, havia dois instrutores e três monitores, então eram em cinco, achei que foi o suficiente".

\section{Revisão da aula passada}

Foi questionado aos participantes sobre a revisão da aula passada que o instrutor faz no início de cada aula do curso de informática básica, de acordo com os comentários, as revisões ajudam a lembrar do que foi visto. Ficou clara a importância da revisão para os ex-alunos e que esse aspecto deve estar presente do curso de smartphone.

\section{Uso de analogias}

Foi perguntado aos participantes se eles gostariam que em um possível curso de smartphone para idosos, fosse mantido o uso de analogias utilizadas no curso de informática básica, por exemplo: a comparação entre o envio de e-mail e o envio de cartas pelos correios, o instrutor explicava que para o envio de uma carta pelos correios era preciso o endereço de destino, de forma parecida, para enviar um e-mail é preciso do endereço de $e$-mail da pessoa ou empresa. Dessa forma, foram utilizados os termos "analogia" e "comparação".

Quanto à essa questão, os participantes concordaram com a importância de manter o uso de analogias para o curso de smartphone para idosos, porém foi observado que as respostas dos participantes foram difusas e pareceu que estes não absorveram completamente o sentido dessa questão: uso de analogias nas aulas.

\section{Receios}

Os participantes foram questionados sobre se há algum receio ao interagir com o smartphone, não houve nenhum relato a respeito de receio de cometer erros de interação, mas houveram reclamações em relação à vírus, propagandas enganosas e spams. A Senhora 1 disse: "tenho receios de abrir imagens, ou navegar em sites pelo smartphone, pois aparece muita propaganda ou mulher pelada." A Senhora 3 comentou: "Quando aparece essas propagandas eu já fecho."

Além do incômodo com spam, e propaganda pornográfica, os participantes expuseram uma grande preocupação com tentativas de roubo pelo smartphone, a Senhora 4 disse: "já me mandaram pelo smartphone uma mensagem: aqui é da NET, queremos fazer uma promoção pra você. O número era de São Paulo, o que tem haver eles me mandarem mensagem aqui em Curitiba? Como descobriram meu número? Deve ser golpe!"

Os comentários evidenciaram a importância de que seja abordado esse tema no curso de smartphone: alertas e cuidados a fim de evitar fraudes e disseminação de vírus.

\section{Adicionar contato de parente em redes sociais} Durante o curso de informática básica para a pessoa idosa, foi observado vários momentos que os alunos pediam auxílio para encontrar parentes em redes sociais ou enviar $e$-mails para familiares e amigos, os participantes foram questionados se seria importante ter algum conteúdo que abordasse esse assunto nos smartphones como: adicionar e iniciar uma conversa por um app e criação de grupos de conversa.

Realização:




\section{$16^{\circ}$ \\ ERGODESIGN USIHC CINAHPA}

Sobre esse assunto o Senhor 3 disse que: "seria interessante reforçar como adicionar contatos nas redes sociais." A Senhora 2 completou: "seria interessante ter no curso de smartphone, conteúdo de como faz essas coisas, apesar de que eu já sei fazer." A mesma senhora aproveitou para expressar que o conteúdo que gostaria de saber melhor são as questões dos contatos do smartphone: "gostaria de saber como acontece e no que implica fazer sincronização automática de contatos entre smartphones, ou entre o smartphone e o computador."

De acordo com os comentários, tanto o tema de adição de contatos de parentes em redes sociais quanto a administração dos contatos de agenda nos smartphones, são de interesse desse público e devem ser abordados no possível curso sobre esses aparelhos.

\section{Apostila}

Foi perguntado aos participantes se eles utilizavam a apostila do curso feito de informática básica para anotações, alguns citaram que faziam anotações em cadernos próprios, mas a maioria disse utilizar a apostila para esse ato. Muitos dos participantes disseram ter anotado como liga e desliga os computadores, a Senhora 5 disse anotar somente as senhas (e.g. de e-mail ou Facebook), nesse mesmo sentido a Senhora 4 foi mais detalhista: "anoto nas margens da apostila." Apenas a Senhora 2 fez um comentário divergente: "Não anoto nada, eu tiro foto se precisar."

Muitos participantes elogiaram a apostila cedida pela CELEPAR para o curso, disseram ser bem detalhada com imagens e autoexplicativa, o Senhor 3 disse: "o material ajudou muito para acompanhar a explicação passo-a-passo do instrutor." Os participantes destacaram a importância do uso de imagens que descrevam as funcionalidades do objeto ou ícones, deram como exemplo uma página da apostila do curso de informática que explicava o que faziam algumas teclas do teclado do computador (e.g. a tecla del é utilizada para enviar arquivos para a lixeira e apagar letras à direita do cursor de texto).

O Senhor 1 resumiu: "queremos saber qual é a $16^{\circ}$ Ergodesign - Congresso Internacional de Ergonomia e Usabilidade de Interfaces Humano Tecnológica: Produto, Informações Ambientes Construídos e Transporte

$16^{\circ}$ USIHC - Congresso Internacional de Ergonomia e Usabilidade de Interfaces Humano Computador

CINAHPA | 2017 - Congresso Internacional de Ambientes Hipermídia para Aprendizagem.

função das coisas. Nessa apostila do curso de smartphone, poderia ter imagens de elementos importantes e a explicação sobre eles como: nome do elemento, qual é a função? O que eu faço com isso?"

No próximo item é feita a análise das informações obtidas nessa atividade: é feita uma comparação ao focus group realizado por Kurniawan (2006).

\subsection{Análise do focus group}

Após o relato e conclusão de cada questão discutida no focus group realizado com os participantes, neste item será feita uma comparação entre as técnicas utilizadas nesta pesquisa e na de Kurniawan (2006), destacando similaridades e diferenças.

O pesquisador Kurniawan (2006) e sua equipe de pesquisadores realizaram um focus group com pessoas idosas para compreender como se dá o uso, entendimento e necessidades dessas pessoas em relação à interface dos celulares. $\mathrm{O}$ autor argumenta que o uso dessa técnica resulta em muita informação em um pequeno período de tempo, e é particularmente útil para explorar o grau de consenso do grupo de pessoas em relação à um tópico. Ainda de acordo com o autor, interação é a chave: assim o grupo expressa sua visão de mundo, linguagem e crenças a respeito de uma questão.

A técnica de captura de dados foi semelhante entre as duas atividades, enquanto Kurniawan (2006) utilizou um aparelho de gravação de áudio, o focus group com os ex-alunos da CELEPAR foi gravado pelo gravador de voz de um notebook, em posse do roteirista da equipe de pesquisa.

O pesquisador Kurniawan (2006), relata que iniciou o focus group introduzindo questões abertas (e.g., Descreva os problemas que você experienciou utilizando celulares.) e ocasionalmente passou para tópicos mais específicos, como: existe algum recurso que você desejaria ter, mas não existe no seu celular?

O focus group realizado com ex-alunos da CELEPAR se assemelha com o realizado por
Realização:

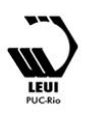




\section{$16^{\circ}$ \\ ERGODESIGN USIHC CINAHPA}

Kurniawan (2006) por ser composto por momentos que agrupam primeiramente questões abertas e gradualmente passando para questões mais específicas. Outra similaridade entre o relato das técnicas, foi que de forma geral, o grupo rapidamente entrava em consenso com a opinião sugerida por um membro do grupo.

Mas há algumas diferenças no que foi observado entre as duas pesquisas: foi observado por Kurniawan (2006) algumas contradições nos comentários dos participantes, por exemplo, enquanto em uma questão todos concordaram que conversas por mensagens influenciam de forma negativa a comunicação pessoal entre pessoas, todos concordaram que Short Messaging Service (SMS) é um dos recursos necessários em um celular.

Contradições dessa natureza não foram observadas na atividade realizada nesta pesquisa. Kurniawan (2006) também relatou que as mulheres participantes do grupo, pediram para serem chamadas de 'mulheres maduras', ao invés do termo 'idosas'. Nenhuma solicitação de mudança de tratamento foi feita pelos ex-alunos da CELEPAR.

Na conclusão do trabalho de Kurniawan (2006), destacaram-se os seguintes aspectos: as idosas estão dispostas a entender mais sobre celulares, são entusiasmadas para aprender e são bem informadas sobre algumas características tecnológicas avançadas desses aparelhos.

No focus group feito com os ex-alunos da CELEPAR os principais objetivos foram: entender as experiências e impressões em relação aos smartphones e expectativas dos idosos em relação à aprendizagem de smartphones. Com os resultados obtidos foi possível elaborar o quadro 1 a seguir, que sintetiza e relaciona assunto relevante discutido no focus group e as sugestões dos participantes.

\begin{tabular}{|l|l|}
\hline \multicolumn{1}{|c|}{$\begin{array}{c}\text { Assunto } \\
\text { relevante }\end{array}$} & \multicolumn{1}{c|}{ Sugestão dos participantes } \\
\hline $\begin{array}{l}\text { Exposição de } \\
\text { conteúdo }\end{array}$ & $\begin{array}{l}\text { Câmera para capturar imagens do instrutor } \\
\text { interagindo no smartphone. Utilização de } \\
\text { projetor multimídia, projetando a imagem da }\end{array}$ \\
\hline
\end{tabular}

$16^{\circ}$ Ergodesign - Congresso Internacional de Ergonomia e Usabilidade de Interfaces Humano Tecnológica: Produto, Informações Ambientes Construídos e Transporte

$16^{\circ}$ USIHC - Congresso Internacional de Ergonomia e Usabilidade de Interfaces Humano Computador

CINAHPA | 2017 - Congresso Internacional de Ambientes Hipermídia para Aprendizagem.

\begin{tabular}{|l|l|}
\hline & câmera no quadro branco ou parede. \\
\hline $\begin{array}{l}\text { Material } \\
\text { impresso }\end{array}$ & $\begin{array}{l}\text { Apostila semelhante à do curso de informática } \\
\text { básica: começando do básico. Deve conter } \\
\text { pelo menos uma página contendo ícones e } \\
\text { botões do smartphone, descrevendo suas } \\
\text { funções. }\end{array}$ \\
\hline $\begin{array}{l}\text { Formato de sala } \\
\text { de aula }\end{array}$ & Disposição dos alunos em formato de "u". \\
\hline $\begin{array}{l}\text { Duração do curso } \\
\text { e tempo de aula }\end{array}$ & $\begin{array}{l}\text { Quatro dias de curso. Cada dia de aula deve } \\
\text { ter 3 horas de duração, com intervalo. }\end{array}$ \\
\hline $\begin{array}{l}\text { Atendimento } \\
\text { individual e } \\
\text { melhores formas } \\
\text { de tirar dúvidas }\end{array}$ & $\begin{array}{l}\text { Ter em sala no mínimo 5 pessoas entre } \\
\text { instrutores e monitores para auxiliar } \\
\text { individualmente os alunos quando o aluno } \\
\text { chamar ou a busca por ajuda for percebida. }\end{array}$ \\
\hline $\begin{array}{l}\text { Revisão de aula } \\
\text { passada }\end{array}$ & $\begin{array}{l}\text { Deve conter breve revisão da aula anterior no } \\
\text { início de cada aula. }\end{array}$ \\
\hline Uso de analogias & As analogias devem ser utilizadas. \\
\hline
\end{tabular}

Quadro 1 - Assuntos e sugestões relevantes discutidos. Fonte: Adaptado de Rocha (2017).

\section{Conclusão}

Esta pesquisa foi feita em busca de expor as preferências de aprendizado de idosos em relação aos smartphones, com a intenção de que o aprendizado sobre esses aparelhos, possibilite maior socialização e autonomia dessas pessoas.

O uso da dinâmica focus group cumpriu com o propósito de gerar discussões a respeito dos temas abordados. $\mathrm{O}$ estimulo à verbalização promovido pelo moderador foi essencial para que as opiniões e sugestões dos participantes pudessem aparecer surgir e contribuir com o estudo. A abordagem utilizada pela equipe de pesquisa na dinâmica se baseou em: paciência, educação e estímulos encorajadores (e.g. discutir sobre adição de parentes em redes sociais), pareceu contribuir com a verbalização.

O objetivo deste trabalho foi entender as experiências e impressões em relação aos smartphones e expectativas dos idosos em relação à aprendizagem de smartphone. Com base nas discussões e sugestões obtidas dos participantes do focus group, é possível afirmar que o objetivo deste artigo.

As informações obtidas com o focus group foram utilizadas posteriormente em uma reunião de planejamento com os instrutores do curso de
Realização:

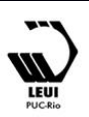




\section{$16^{\circ}$ \\ ERGODESIGN USIHC CINAHPA}

informática básica e redes sociais da CELEPAR, para a elaboração de um curso piloto de smartphone, ação que faz parte do método da dissertação de Rocha (2017).

Esta pesquisa contribuiu com as sugestões de como os idosos gostariam de aprender smartphones, possibilitando a elaboração e surgimento de cursos baseados nessas sugestões, e assim capacite os idosos a interagir com esses aparelhos.

O conteúdo da atividade descrita neste artigo, sinaliza itens que necessitam de maior atenção dos designers de interface para atender às preferências do público idoso, principalmente quanto à personalização.

Espera-se que Instituições educacionais ou outras instituições que têm projetos sociais, possam utilizar as sugestões dos participantes idosos na elaboração de cursos de smartphones para esse público.

Os pesquisadores esperam que este trabalho possa inspirar também pesquisadores, para que busquem propostas de soluções ou melhorias para o público idoso, com processos de ensino-aprendizagem e acessibilidade em interfaces de smartphones, entre outras possibilidades que possam facilitar a socialização, autonomia e domínio desse público com as novas tecnologias.

\section{BIBLIOGRAFIA}

CENSO DEMOGRÁFICO 2010. Características da população e dos domicílios: Resultado do universo. Rio de Janeiro: IBGE, 2011. Disponível em: <http://censo2010.ibge.gov.br/noticiascenso ?busca $=1 \& \mathrm{id}=3 \&$ idnoticia $=1866 \& \mathrm{t}=$ dadospreliminares-censo-2010-ja-revelam-mudancaspiramide-etaria-brasileira\&view $=$ noticia $>$. Acesso em: 5. Set. 2014.

GRAGNOLATI, M.; JORGENSEN, O.; ROCHA, R.; FRUTERO, A. Envelhecendo em um Brasil mais Velho: Implicações do envelhecimento $16^{\circ}$ Ergodesign - Congresso Internacional de Ergonomia e Usabilidade de Interfaces Humano Tecnológica: Produto, Informações Ambientes Construídos e Transporte

$16^{\circ}$ USIHC - Congresso Internacional de Ergonomia e Usabilidade de Interfaces Humano Computador

CINAHPA | 2017 - Congresso Internacional de Ambientes Hipermídia para Aprendizagem. populacional para o crescimento econômico, a redução da pobreza, as finanças públicas e a prestação de serviços. Washington: Banco Mundial, 2011.

KURNIAWAN, S. An exploratory study of how older women use mobile phone. In: 8TH INTERNATIONAL CONFERENCE: UBICOMP 2006, 8., 2006, Orange Country. Proceedings... .Berlin: Springer Berlin Heidelberg, 2006. p. 105 122.

\section{MARTIN, B.; HANINGTON, B. Universal}

Methods of Design: 100 Ways to Research Complex Problems, Develop Innovative Ideas, and Design Effective Solutions. Rockport Publishers: Beverly, 2012. 208 p.

PHIRIYAPOKANON, T. Is a big button interface enough for eldery users?:Towards user interface guidelines for eldery users. 2011. 61 f. Dissertação (Mestrado) - Curso de Computer Engineer, Computer Science And Engineering, Mälardalen University, Västerås, 2011.

\section{ROCHA, E. Capacitando Idosos a Utilizar}

Smartphone: Uma Abordagem Utilizando o Design Instrucional Contextualizado e Flexível. 2017. 116 f. Dissertação (Mestrado) - Curso de Design, Universidade Federal do Paraná, Curitiba, 2017.

TANG, C.; LEUNG, R.; HADDAD, S.; MCGRENERE, J. 2013. What motivates older adults to learn to use mobile phones. Disponível em:

<https://www.cs.ubc.ca/ joanna/papers/GRAND20 12_Tang_MobilePhone.pdf $\geq$. Acesso em: $04 \mathrm{dez}$, 2015.

\section{Agradecimentos}

Os autores agradecem à CAPES pelo apoio financeiro e concessão de bolsa e à CELEPAR pela colaboração com a aplicação do método. 